Please download and read the instructions before proceeding to the peer review

\title{
Are BK (big potassium)-type Ca2+-activated potassium channels a viable target for the treatment of epilepsy?
}

\begin{tabular}{|r|l|}
\hline Journal: & Expert Opinion On Therapeutic Targets \\
\hline Manuscript ID: & EOTT-2014-0274.R1 \\
\hline Manuscript Type: & Review \\
\hline Keywords: & $\begin{array}{l}\text { BK potassium channels, Epilepsy, Seizures, BK channel modulators, } \\
\text { Antiepileptic drug (AED) }\end{array}$ \\
\hline
\end{tabular}

SCHOLARONE $^{\text {m }}$
Manuscripts

URL: http://mc.manuscriptcentral.com/eott Email: Claudia.Palmer@informa.com 
The BK channel protein is a multimeric structure (homotetramer) composed of four identical pore-forming a subunits (BKa), encoded by a single gene (Slo1, KCNMA1). Each BKa has seven trans-membrane segments (S0-S6) and a large intracellular C-terminus region. The BKa protein shows three main structural domains, each with a distinct function. The voltage-sensing domain (VSD) is located within the S1-S4 transmembrane segments, able to sense membrane potential. The S5-S6 segments form the pore gate domain (PGD) including the activation gate, which controls $\mathrm{K}+$ flux through the channel. The $\mathrm{S} 6$ segment serves as the major structural determinant for the channel gate. The primary voltage sensor is located on the S4 helix, which contains many positively charged residues, but only one of these participates in voltage sensing. The membrane-spanning domains VSD and PGD, interact through the S4-S5 linker and S6, and the hydrophobic segment (SO) leads to an extracellular NH2 terminus. The third domain is the cytosolic domain (CTD), which enables the channel to respond to changes in [Ca2+]i and other stimuli. The intracellular Cterminus has two tandem RCK (regulator of K+ conductance) domains, RCK1 and RCK2, folded tightly against each other. Channel sensitivity to $\mathrm{Ca} 2+$ is determined by a gating ring of eight RCK domains from the four assembled a subunits; this gating ring is subjected to an expansion during channel gating. RCK2 domains have an aspartate-rich region that forms the 'Ca2+ bowl', showing a high Ca2+ affinity. A lowaffinity $\mathrm{Ca} 2+$ recognition site has also been identified within the RCK1 domain, where another high-affinity $\mathrm{Ca} 2+$ site is also present. RCK1 also mediates the channel's sensitivity to $\mathrm{Mg} 2+, \mathrm{Zn} 2+$ and $\mathrm{Cd} 2+$. The four $\beta$ subunits ( $\beta 1-4)$ are encoded by a specific gene KCNMB1-4 (human) or kcnmb 1-4 (mouse). These BK channel subunits have two transmembrane domains (TM1 and TM2) connected by a large loop on the extracellular side. $\beta$-subunits also show an intracellular $\mathrm{N}$-terminus and $\mathrm{C}$-terminus. Each $\beta$-subunit is located between two adjacent a-subunits. $y$ subunits contain a single transmembrane domain, an $\mathrm{N}$-terminal extracellular LRRD (leucine-rich repeat domain), and a short C-terminal tail. $389 \times 245 \mathrm{~mm}(72 \times 72$ DPI $)$ 


\title{
Expert Opinion On Therapeutic Targets
}

\section{Are BK (big potassium)-type $\mathrm{Ca}^{2+}$-activated potassium channels a viable target for the treatment of epilepsy?}

\begin{abstract}
Introduction: $\mathrm{BK}$ (big potassium) channels are $\mathrm{Ca}^{2+}$-activated $\mathrm{K}^{+}$channels widely expressed in mammalian cells. They are extensively distributed in the CNS, the most abundant level being found in brain areas largely involved in epilepsy, namely cortex, hippocampus, piriform cortex, and other limbic structures. BK channels control action potential shape/duration, thereby regulating membrane excitability and $\mathrm{Ca}^{2+}$ signalling.

Areas Covered: The potassium channel superfamily represents a rich source of potential targets for therapeutic intervention in epilepsy. Some studies have identified alterations in BK channel function, therefore, supporting the development of drugs acting on these channels for epilepsy treatment.
\end{abstract}

Expert Opinion: The actual sketch is intriguing and controversial, since mechanisms altering the physiological role of BK channels leading to either a loss- or gain-of-function have both been linked to seizure onset. Not many studies have been performed to unravel the efficacy of drugs acting on these channels as potential antiepileptics; however, paradoxically, efficacy has been demonstrated for both BK channel openers and blockers. Furthermore, their potential usefulness in preventing epileptogenesis has not been investigated at all. Substantial data on risks and benefits of modulating these channels are urgently needed to draw a definitive conclusion on whether BK channels are a viable future target for the treatment of epilepsy.

Keywords: BK potassium channels; Epilepsy; Seizures; BK channel modulators; Antiepileptic drug (AED). 


\section{List of abbreviations}

$\left[\mathrm{Ca}^{2+}\right]=$ Calcium concentration

$\left[\mathrm{Ca}^{2+}\right]_{\mathrm{i}}=$ Intracellular calcium concentration

AEA $=N$-arach-idonylethanolamine

$\mathrm{AED}=$ Antiepileptic drug

AHP $=$ afterhyperpolarizationAfterhyperpolarization

Aps-APs $=$ Action potentials

4-AP=4-Aminopyridine

ASN $=$ Asparagine

Asp $=$ Aspartate

ATP $=$ Adenosine tri-phosphate

BK, BKCa, MaxiK, Slo1, KCa1.1, KCNMA1 = Big potassium channel or Big conductance calcium-activated potassium channel

$\mathrm{BK} \alpha=\alpha$ subunit of BK channel

C-linker $=$ Carboxy linker

C-terminus $=$ Carboxy terminus

$\mathrm{CA}=$ Carbonic anhydrase

$\mathrm{CA} 1=$ Cornus ammonis

$\mathrm{Ca}^{2+}=$ Calcium ions

$\mathrm{Ca}_{\mathrm{v}}=$ Calcium channel

$\underline{\mathrm{cAMP}}=$ Cyclic adenosine monophosphate

$\mathrm{CB}=$ Cannabinoid receptors

| $\mathrm{CBD}=\underline{\text { Ceannabidiol }}$

$\mathrm{CBDV}=$ Cannabidivarin

$\mathrm{Cd}^{2+}=$ Cadmium ions

| cGMP = eyclieCyclic-guanosine monophosphate

$\mathrm{CNS}=$ Central nervous system 
COX-2 = Cyclooxygenase-2

cryo-EM = cryo-Electron Microscopy

$\mathrm{CTD}=$ Cytosolic domain

DHA = docosahexaenoic-Docosahexaenoic acid

dSlow $=$ dresephila-Drosophila Slowpoke

$\mathrm{ER}=$ Endoplasmic reticulum

$\mathrm{fAHP}=$ fast afterhyperpolarization

GABA $=\gamma$-Aminobutyric acid

GH3 = Rat pituitary cells

Glu $=$ Glutamate

GMP = Guanosine monophosphate

$\mathrm{H}^{+}=$Hydrogen ions

hSlow = human Slowpoke

$\mathrm{IK}=$ Intermediate potassium channel or Intermediate conductance calcium-activated potassium channel

$\mathrm{IP}_{3}=$ Inositol tri-phosphate

$\mathrm{K}^{+}=$Potassium ions

$\mathrm{KCa}=$ Calcium-activated potassium channel

$\mathrm{K}_{\mathrm{V}}$ or $\mathrm{KCNQ}=$ Potassium channel

LRRCs $=$ Leucine-rich repeat-containing subunits

$\mathrm{mAHP}=$ medium afterhyperpolarization

MAPK $=$ Mitogen-activated protein kinase

MES $=$ Electroshock-induce seizures

$\mathrm{Mg}^{2+}=$ Magnesium ions

mitoBK $=$ mitochondria Big Potassium channel

$\mathrm{ms}=$ millisecond

$\mathrm{mSlow}=$ mice Slowpoke

$\mathrm{Na}^{+}=$Sodium ions

$\mathrm{Na}_{\mathrm{v}}=$ Sodium channel

$\mathrm{NE}=$ - Nuclear envelope

$\mathrm{NH}_{2}$ or $\mathrm{N}$ terminus $=$ Amino terminus

NMDA $=$ N-methyl-D-aspartate

$\mathrm{NO}=$ Nitric oxide

PEA $=N$-palmitoylethanolamine

PGD $=$ Pore gate domain

PI 3-kinase $=$ Phosphoinositide 3-kinase

$\mathrm{PKA}=$ Protein kinase $\mathrm{A}$

$\mathrm{PKC}=$ Protein Kinase $\mathrm{C}$

PPAR- $\alpha=$ Peroxisome proliferator-activated receptor-alpha

$\mathrm{PTZ}=$ Pentylenetetrazole

$\mathrm{RCK}=$ Regulator of $\mathrm{K}^{+}$Conductance

ROS $=$ Reactive oxygen species

$\mathrm{s}=$ second

$\mathrm{S}=$ trans-membrane segment

sAHP = slow afterhyperpolarization

$\mathrm{SK}=$ Small potassium channel or Small conductance calcium-activated potassium channel

Slo $=$ Slowpoke

STREX $=$ Stress axis hormone-regulated exon

$\mathrm{TM}=$ Transmembrane domain

$\mathrm{TRPV}=$ Transient receptor potential vanilloid 
$\mathrm{VSD}=$ Voltage-sensing domain

$\mathrm{Zn}^{2+}=$ Zinc ions

ZNS $=$ Zonisamide

$\tau=$ Time constant

\section{Introduction}

Calcium-activated potassium channels $(\mathrm{KCa})$ are a large and diversified family of ion channels that transduce increases in intracellular $\mathrm{Ca}^{2+}\left(\left[\mathrm{Ca}^{2+}\right]_{i}\right)$ into changes in membrane potential (hyperpolarization) that can then influence the duration and frequency of action potentials (APs) in excitable cells (both pre- and postsynaptically) and thus exert an important influence on their functional properties. According to their single channel conductance, $\mathrm{Ca}^{2+}$ activated $\mathrm{K}^{+}$channels can be divided into three subfamilies: small conductance (SK: 2-25 pS), intermediate conductance (IK: 25-100 pS) and large conductance (BK: 100-300 pS) subtypes; each subgroup also exhibit distinct pharmacological and biophysical characteristics ${ }^{1-4}$. In addition to their important regulatory roles, $\mathrm{Ca}^{2+}$-activated $\mathrm{K}^{+}$channels also have an important potential as targets for novel therapeutic drugs in health and disease ${ }^{5-7}$. The BK channel (also referred to as $\mathrm{BKCa}$, MaxiK, Slo1, $\left.\mathrm{KCa}_{1.1}\right)$ was the first of the $\mathrm{Ca}^{2+}$-activated $\mathrm{K}^{+}$channels to be identified and is one of the most widely expressed channels in mammalian cells and tissues such as neurones, skeletal, smooth and cardiac muscles, exocrine cells, and the inner sensory hair cells of the cochlea ${ }^{8-10}$. BK channels are also unique in being activated both in response to membrane depolarization and an increase of $\left[\mathrm{Ca}^{2+}\right]_{i}$ intracellular $\left[\mathrm{Ca}^{2+}\right]$ (allosteric activation); in contrast, SK and IK channels are voltage-insensitive and are solely activated by increases in $\left[\mathrm{Ca}^{2+}\right]_{\mathrm{i}}$. Voltage and $\mathrm{Ca}^{2+}$ gating sites are separately coupled to the channel protein and trigger several conformational changes to activate the BK channel ${ }^{9}$. Even though experimentally, membrane voltage and fluctuations in $\left[\mathrm{Ca}^{2+}\right]_{\mathrm{i}}$ by themselves are able to alter BK open channel probability, many observations have demonstrated that both membrane 


\section{Expert Opinion On Therapeutic Targets}

depolarization and micromolar rises in $\left[\mathrm{Ca}^{2+}\right]_{\mathrm{i}}$ are specifically required to open $\mathrm{BK}$ channels under physiological conditions. Accordingly, BK channels, depending on their location, connect changes in $\left[\mathrm{Ca}^{2+}\right]_{\mathrm{i}}$ to outward hyperpolarizing $\mathrm{K}^{+}$currents that can affect postsynaptic cell firing as well as presynaptic neurotransmitter release ${ }^{7,11}$. Moreover, intracellular $\mathrm{Mg}^{2+}$ and $\mathrm{H}^{+}$ions are also able to regulate BK channels; specifically, millimolar intracellular $\mathrm{Mg}^{2+}$ (binding to a site distinct from the $\mathrm{Ca}^{2+}$ binding site), can activate the $\mathrm{BK}$ channel ${ }^{12}$, and decreasing or increasing intracellular $\mathrm{pH}$ (acting via the RCK1 sensor), enhances or reduces BK channel opening, respectively ${ }^{13}$. This sensitivity of BK channels to intracellular $\mathrm{H}^{+}$ions could be an important mechanism contributing to termination of epileptic seizure events, known to be associated with intracellular neuronal acidification ${ }^{14}$. BK channel functions can also be regulated by ubiquitination and palmitoylation, which seem to control the cell surface expression and activity of $\mathrm{BK}$ channel proteins. Indeed, myristoylation seems to allow endocytosis $^{15-17}$. Additionally, other endogenous mediators such as arachidonic acid, NO, zinc, GMP, cGMP and cAMP-mediated phosphorylation of the channel may regulate BK channel activity ${ }^{13}$.

In neurones, the activation of BK channels results in an increased efflux of $\mathrm{K}^{+}$from the cell (outward current); as a consequence, the membrane potential is driven in a negative direction (decreased cell excitability) and voltage-dependent $\mathrm{Na}^{+}$and $\mathrm{Ca}^{2+}$ channels are closed, so the probability that an AP is triggered is decreased. Therefore, these channels function as "negative feedback regulators" of membrane potential and $\left[\mathrm{Ca}^{2+}\right]_{i}$ and play crucial roles in several physiological functions, such as controlling the inter-spike interval and spike frequency adaptation, neurotransmitter release, endocrine secretion, hair cell tuning frequencies, as well as urinary bladder and respiratory neurone network 'tone'.

More recently, it has been recognised that BK channels can associate with a variety of $\mathrm{G}$ protein-coupled membrane receptors (mainly on peripheral smooth muscle, but also in the 


\begin{abstract}
brain) including muscarinic acetylcholine receptors, $\beta$-adrenergic receptors, thromboxane A2
\end{abstract} receptors and angiotensin II receptors, indicating a potential involvement in a wide variety of physiological functions in addition to regulation of cell excitability. Furthermore, they appear to complex with a variety of cytosolic proteins controlling cellular function, proteins of the endoplasmic reticulum, nucleus and mitochondria as well as kinases involved in cell death/survival, further raising their importance in maintaining normal physiological metabolic processes. It is not too surprising therefore, that identified BK channel malfunction is increasingly being linked with important human brain, metabolic and cardiovascular diseases including obesity and cancer and that much interest is now being shown in BK channels as potential therapeutic targets ${ }^{18}$. Dysfunction of BK channels has been implicated in the onset of certain epilepsies, motor deficits, hypertension, asthma, abnormal circadian rhythms, defects in immunity and other disorders ${ }^{19-22}$. Defective BK channels are also thought to contribute to the physiopathology of neurological disorders such as schizophrenia ${ }^{23}$, autism and mental retardation ${ }^{24}$.

Epilepsy involves alterations of normal physiological processes in the brain. An epileptic seizure is produced by synchronous and sustained firing of a population of neurones. Both $\underline{\text { excitatory and inhibitory influences may be altered, creating a predisposition towards }}$ $\underline{\text { excessive synchrony within neuronal populations }}^{25}$. About 50 million people in the world now have epilepsy, and it is estimated that 40-70 new cases per 100,000 individuals in the general population will acquire the disease every year in developed countries, with the risk being $\underline{\text { twice as high in developing countries }}^{26}$. Although approximately $70-80 \%$ of humans with new-onset epilepsy eventually enter sustained seizure remission during treatment, important, unmet needs exist in the drug treatment of epilepsy, including the development of more $\underline{\text { effective and safer AEDs }}^{27,28}$ 


\section{Expert Opinion On Therapeutic Targets}

\section{Molecular structure of BK channels}

Structurally, BK channels share some similarity with the voltage and ligand-gated $\mathrm{K}^{+}$channel superfamily (Figure 1). BK channel proteins are multimeric structures (homotetramers) composed of four identical pore-forming $\alpha$ subunits (BK $\alpha$ ) each comprising of seven transmembrane segments (S0-S6) and a large intracellular C-terminus region ${ }^{19}$. BK $\alpha$ can be coassembled with four different auxiliary modulatory $\beta$-subunits $(\beta 1-\beta 4)$, as well as a family of leucine-rich repeat-containing subunits (LRRCs) also called $\gamma$-subunits. Each type of $\beta$ - and $\gamma$-subunit displays a distinct tissue-specific expression pattern and differently affects the conductance properties, inactivation, gating kinetics and pharmacology of the assembled channel $^{29-31}$. $\beta 2-4$ subunits are neuronally expressed, whereas $\beta 1$ subunits are mainly distributed in smooth muscle cells ${ }^{9}$. BKa is encoded by a single gene (Slo1, KCNMA1), with 27 constitutive exons and multiple alternative exons spanning. The BK gene was first discovered in Drosophila as the slowpoke mutation (dSlo) and later was identified also in mice (mSlo1) and humans (hSlo1). In mammals, the constitutive exons of the BKa gene code for proteins with $\sim 98 \%$ amino acid sequence homology. Each of these constitutive exons is designed for a specific function, like the conduction pore, voltage sensor, ' $\mathrm{Ca}^{2+}$ bowl' and S0 trans-membrane segments ${ }^{32}$.

Recently, cryo-electron microscopy (cryo-EM) and X-ray crystallography studies of the BK $\alpha$ protein have revealed three main structural domains with distinct function and the assembly 
and interactions among these domains $\mathrm{s}^{33,34}$. These interactions are critical for activation of the channel in response to physiological changes of membrane potential, and intracellular levels of $\mathrm{Ca}^{2+}$ and $\mathrm{Mg}^{2+}$. Briefly, the voltage-sensing domain (VSD) characteristically located within the trans-membrane segments S1-S4 is able to sense membrane potential, whereas the segments S5-S6 form the pore gate domain (PGD) and within its resides, the activation gate, which controls the $\mathrm{K}^{+}$flux through the channel ${ }^{32,35,36}$. Moreover, S6 is believed to serve as the major structural determinant for the channel gate. The primary voltage sensor is located on the S4 helix, which contains many positively charged residues (basic residues) but only one of these, has been shown to participate in voltage sensing ${ }^{37}$. VSD and PGD, also called the membrane-spanning domains, can interact through the S4-S5 linker and $\mathrm{S6}^{37}$. Furthermore, BK channels have a hydrophobic segment (S0) that leads to an extracellular $\mathrm{NH}_{2}$ terminus and additional four intracellular hydrophobic segments (S7-S10) in the Cterminus. The first transmembrane segment, S0, is required for $\beta$-subunit modulation and can participate to modulate voltage sensitivity. The third domain is the cytosolic domain (CTD), which confers on the BK channels the ability to respond to changes in $\left[\mathrm{Ca}^{2+}\right]_{\mathrm{i}}$ and other stimuli.

The crystal structure of the BK channel in the intracellular C-terminus has defined two tandem RCK (regulator of $\mathrm{K}^{+}$conductance) domains, RCK1 and $\mathrm{RCK} 2^{36}$. These tandem domains are folded tightly against each other and channel sensitivity to $\mathrm{Ca}^{2+}$ is determined by a gating ring of eight RCK domains from four assembled $\alpha$ subunits. The gating ring formed by RCK1 and RCK2 is subjected to an expansion during the channel gating. RCK2 domains have an aspartate-rich region that forms the ' $\mathrm{Ca}^{2+}$ bowl', which is located in the distal region of the C-terminus (S9-S10) and confers a high $\mathrm{Ca}^{2+}$ affinity. The low-affinity $\mathrm{Ca}^{2+}$ recognition site has been identified within the RCK1 domain, where another high-affinity $\mathrm{Ca}^{2+}$ site is also present. RCK1 also mediates the channel's sensitivity to $\mathrm{Mg}^{2+}, \mathrm{Zn}^{2+}$ and $\mathrm{Cd}^{2+}$. Most likely, 


\section{Expert Opinion On Therapeutic Targets}

$\mathrm{Mg}^{2+}$ binds to a site in between VSD (Asp99 and ASN172) and RCK1 (Glu 374 and Glu 399), allowing it to influence the VSD with an electrostatic interaction, and as a consequence, the BK channel can be opened. Hence, it has been established that the interaction between VSD and CTD may occur during channel gating ${ }^{36,38-40}$. Likewise, PGD and CTD can connect through the C-linker peptide and its length affects the activity of BK channel. Moreover, other residues located in the $\mathrm{C}$-terminus allow the linking with molecules, such as heme and carbon monoxide, which modulate the gating properties of the BK channels ${ }^{41}$. The cytosolic region also includes phosphorylation sites for protein kinase A (PKA) and protein kinase C (PKC). Generally, PKA phosphorylation leads to BK channel enhancement, whereas PKC phosphorylation leads to channel inhibition.

The four $\beta$-subunits ( $\beta 1-4)$ are encoded by a specific gene KCNMB1-4 (human) or kcnmb1-4 (mouse). These BK channel subunits have two transmembrane domains ( $\underline{\text { STM1 }}$ and $\underline{\mathrm{STM}} 2$ ) connected by a large loop on the extracellular side. Moreover, $\beta$-subunits show an intracellular $\mathrm{N}$-terminus and $\mathrm{C}$-terminus. Each $\beta$-subunit is located between two adjacent $\alpha$ subunits and alters the pharmacological sensitivity of BK channels, as well as their regulation by phosphorylation, which involve multiple distinct mechanisms. For example, BK $\beta$ subunits 1,2 and 4 seem to stabilize the BK VSD in the active conformation, whereas BK $\beta 2$ and 3 subunits confer BK channel inactivation via an N-terminal inactivation ball, and related minor $\mathrm{K}^{+}$efflux ${ }^{31,42,43}$. In most tissues, the BK $\alpha$ subunit can be linked with up to three $\beta$-subunits ${ }^{42}$. So far, it has not been possible to elucidate how the interdomain interactions among the three main domains VSD, CTD, and PGD are modified by $\beta$-subunits to influence channel activation $^{7,9}$. The ability of $\gamma$-subunits to bind and to modify BK channel kinetics and gating behaviour still remains unclear. However, it seems that all $\gamma$-subunits enhance voltagedependent activation of BK channels ${ }^{30,31}$.

[Figure 1 near here] 


\section{BK channels in the central nervous system: distribution and pharmacological properties}

BK channels are widely distributed both in the central nervous system (CNS) and peripheral nervous system, with consistent expression both in the cell body and at the presynaptic terminal. BK channels are closely co-localized near the $\mathrm{Ca}^{2+}$ sources, such as voltagedependent $\mathrm{Ca}^{2+}$ channels, ryanodine receptors, $\mathrm{IP}_{3}$ receptors and $\mathrm{N}$-methyl-D-aspartate (NMDA)-type glutamate receptors. The voltage-gated calcium channel $\left(\mathrm{Ca}_{\mathrm{v}}\right)$ subtypes that interact with $\mathrm{BK}$ channels differ from neurone to neurone and comprise of $\mathrm{Ca}_{\mathrm{v} 1.2}$ (L-type), $\mathrm{Ca}_{\mathrm{v} 2.1}$ (P/Q-type), $\mathrm{Ca}_{\mathrm{v} 2.2}\left(\mathrm{~N} \text {-type) and } \mathrm{Ca}_{\mathrm{v} 3} \text { (T-type }\right)^{44}$. Abundant levels of $\alpha$-subunits in the CNS have been identified in the cortex, hippocampus, olfactory system, piriform cortex, and other limbic structures. Both in cortex and hippocampus, $\alpha$-subunits are mostly expressed in glutamatergic synapses, whereas in the cerebellum, they are expressed at GABAergic nerve terminals ${ }^{3,44-46}$. In CNS areas, such as cortex, hippocampus and cerebellum, $\alpha$-subunits have also been detected in the inner mitochondrial membrane (mitoBK). Similarly to BK, mitoBK is selectively permeable to $\mathrm{K}^{+}$and is activated by both voltage and $\left[\mathrm{Ca}^{2+}\right]_{\mathrm{i}}$. It seems that there are, at least, two type of mitoBK in the brain, but so far, their structure remains unknown ${ }^{47}$.

The $\beta$-and $\gamma$-modulatory subunits have a limited expression pattern in the brain. The $\beta 4-$ subunit is the most expressed neuronal subunit. This subunit, in a $\mathrm{Ca}^{2+}$ concentrationdependent manner, produces mixed effects on BK channel gating. In particular, in the presence of a low local $\mathrm{Ca}^{2+}$ concentration, the $\beta 4$-subunit decreases the activation of $\mathrm{BK}$ channels, whereas at high $\mathrm{Ca}^{2+}$ concentration, the $\mathrm{BK}$ channel activation is increased. The other subunits expressed in the brain are $\beta 2$ and $\beta 3$, whereas smooth muscle cells primarily express the $\beta 1$ subunit $^{29,48}$. 


\section{Expert Opinion On Therapeutic Targets}

Electrophysiological and pharmacological evidence suggests that $\alpha$-subunit interactions with $\beta 2$ - and $\beta 4$-subunits determine the BK channel subtypes observed in the CNS. Essentially, three central neuronal BK channel subtypes can be identified: 1) type I showing rapid activation and N-type "ball-and-chain" inactivation $\left.(\alpha+\beta 2)^{49} ; 2\right)$ or the non-inactivating type I ( $\alpha$ alone) and 3$)$ type II $(\alpha+\beta 4)$. Paxilline (an indole diterpene alkaloid derived from Penicillium paxilli), has been identified as a useful, selective and reversible blocker of type I and type II BK channels ${ }^{50}$. The $\beta 2$-subunit is able to confer N-type inactivation to BK channels, which are sensitive to block by iberiotoxin (from the red scorpion Buthus tamulus) and charybdotoxin (from the scorpion Leiurus quinquestriatus). In the CNS, these types of BK channel are mainly localized in the hippocampus; and they seem to be responsible for the early repolarization after a short burst train of APs-in a train. Interestingly, the $\beta 4$-subunit renders type II BK channels refractory to iberiotoxin and charybdotoxin block, but they are selectively inhibited by martentoxin, a peptide purified from the venom of the East-Asian scorpion Buthus martensi $i^{51}$. Moreover, type II BK channels are less sensitive to $\left[\mathrm{Ca}^{2+}\right]_{\mathrm{i}}$ and have slow gating kinetics.

Type I BK channels have relatively fast gating kinetics and are sensitive to scorpion venom block $^{35,43,46}$. The study of the role of these channels in the CNS has been facilitated by iberiotoxin and other inhibitors, such as paxilline, lolitrem B (from the ryegrass fungus Acremonium lolii) and penitrem A (from Penicillium cyclopium) ${ }^{52}$. The principal role of BK channels is to generate the fast neuronal afterhyperpolarization (fAHP) seen immediately after an AP. AP repolarization and the fAHP participate significantly to affect AP shape and duration. Generally, BK channels are relatively slowly activated during an AP; the fast AP upstroke and consequent $\mathrm{Ca}^{2+}$ influx also activates other $\mathrm{Ca}^{2+}$-dependent conductances such 
as SK channels, to contribute towards inhibition of repetitive firing. Thus, BK channels through the control of AP shape and duration have an important function in regulating membrane excitability and $\mathrm{Ca}^{2+}$ signalling ${ }^{10,53}$.

The AHP, following single or longer bursts of APs, is composed of multiple kinetic components that have been well characterized in the hippocampus ${ }^{54}$. In hippocampal CA1 neurones, it was possible to discern three potassium conductances; the fast component (fAHP), that decays with a time constant $\left(\tau_{\text {decay }}\right)$ of $\sim 50 \mathrm{~ms}$, is mediated by BK channels or Mtype $\mathrm{K}^{+}$channels. The two longer-lasting components are both mediated by voltageindependent, $\mathrm{Ca}^{2+}$-activated $\mathrm{K}^{+}$conductances; the intermediate (medium) AHP (mAHP), which has a decay time constant $\left(\tau_{\text {decay }}\right)$ of $\sim 250 \mathrm{~ms}$, activates during the AP-mediated $\mathrm{Ca}^{2+}$ influx, is mediated by SK channels and is blocked by the bee venom toxin, apamin ${ }^{55}$. By contrast, the slow AHP (sAHP) evoked after a longer $(\sim 1 \mathrm{~s})$ burst of APs, shows a prominent activation phase $\left(\tau_{\text {rise }} \sim 600 \mathrm{~ms}\right)$, and decays slowly, persisting for as long as several seconds. In particular, during an AP, membrane depolarization and the increment of cytosolic $\mathrm{Ca}^{2+}$ activate BK channels with a reduction of AP frequency. During a fAHP, the membrane potential is more negative than the normal resting potential, and returns to baseline slowly. In fact, the loss of BK current in a neurone is linked with reduction of the AHP, resulting in a higher AP frequency and enhancement of membrane excitability. This delay of the membrane potential to reach the normal resting potential after depolarization, results in increased interspike intervals and ultimately in control of neuronal excitability ${ }^{53,56,57}$. Following a fAHP, many neurones show a prolonged AHP that is generated by SK channels. This prolonged AHP also plays an important role in controlling spike frequency ${ }^{57}$. 


\section{Expert Opinion On Therapeutic Targets}

BK channels are also involved in the regulation of CNS neurotransmitter release ${ }^{4}$. This activity is correlated with their location around $\mathrm{Ca}_{\mathrm{v}} \mathrm{s}$. It seems that at presynaptic terminals, in response to a prolonged depolarization and $\mathrm{Ca}^{2+}$-influx, $\mathrm{BK}$ channels limit the number of APs and the subsequent influx of $\mathrm{Ca}^{2+}$, thereby decreasing vesicle fusion and therefore, neurotransmitter release. These channels are also capable of enhancing the activity of the $\mathrm{Na}^{+} / \mathrm{Ca}^{2+}$ exchanger to prevent excessive $\left[\mathrm{Ca}^{2+}\right]_{i}$. During massive activation of neurones, i.e. during ischaemia or seizures, BK channels may act as an "emergency" protective system to counteract excitotoxic damage $e^{46,58}$.

Generally, BK channels in the hippocampal CA1 pyramidal cell layer reduce the frequency and duration of APs. However, in the past, experiments in rat CA1 pyramidal cells have remarked on the ability of BK channels to enhance early high-frequency firing. The reason for this facilitation seems to be related to the rapid spike repolarization and fAHP, which can restrict the activation of other slower potassium currents and inactivation of the fast $\mathrm{AP} \mathrm{Na}^{+}$ current $^{46,53}$. Interestingly, blocking the BK-mediated fAHP with paxilline resulted in an impairment of hippocampus-dependent learning during trace eyeblink conditioning in rats ${ }^{59}$.

BK channels have also been localized in the inner mitochondrial membrane, but their exact role in these organelles is unclear. They are, however, known to be important for $\mathrm{Ca}^{2+}$ ion sequestration and for $\mathrm{K}^{+}$transport. The opening of mitoBK channels actually produces a loss (depolarization) of the inner mitochondrial membrane potential, which may have a protective function, fundamental for the regulation of mitochondrial metabolism ${ }^{60}$. Indeed, some findings indicate neuroprotective properties for mitoBK in specific brain structures ${ }^{8,}{ }^{6}$. Pharmacologically, mitoBK channels are unusual, in that they are blocked by iberiotoxin but not by charybdotoxin ${ }^{62}$. It has also been suggested that BK channels are present on the 


\section{BK channels and epilepsy pathophysiology}

Under physiological conditions, through a negative feedback mechanism, BK channels modulate both neuronal membrane potential and intracellular $\mathrm{Ca}^{2+}$ signalling, actions that should in principle, attenuate epileptic seizure bursts. In fact, BK channels, by linking changes in intracellular $\mathrm{Ca}^{2+}$ to a fast hyperpolarizing response, would be expected to decrease or prevent neuronal hyperexcitability that would lead to seizures. Thus, mechanisms altering the physiological role of these channels, such as gene mutations, down or upregulation of channel expression, or defects in channel trafficking and insertion into the plasma membrane could contribute to the onset of seizures, as well as other neurological diseases. In particular, studies have indicated a seizure-related down-regulation of BK channels in the hippocampus of chronically epileptic rats. Moreover, seizure-mediated BK down-regulation of BK channels principally localized at glutamatergic terminals, could also affect neuronal excitability by influencing presynaptic control of glutamate release, with a consequent facilitation of seizure events. Thus, it seems that altered BK channel expression is a plastic modification mechanism that can affect the network excitability in these epileptic $\operatorname{animals}^{64,65}$.

Both gain- and loss-of-function mutation of genes encoding for the BK channel subunits have also been correlated to channelopathies leading to epilepsy disorders. Because the normal function of BK channels generally reduces neuronal excitability, loss-of-function mutations related to these channels gives rise to neuronal hyperexcitability, which can lead to seizures. A single base pair deletion in exon 4 (delA750) of the gene encoding for the $\beta 3$ regulatory 


\section{Expert Opinion On Therapeutic Targets}

In animal models of epilepsy, the loss-of-function mutation has been involved in the development of seizures and related neurological disorders. Intracellular recordings in rat subicular neurones revealed a transient depression of the fast and slow AHP during the course of kindling that may contribute to the induction but not permanence of the kindled state ${ }^{69}$. Moreover, other data associated the loss-of-function mutation with the development of epileptogenesis. In particular, epileptogenesis in mesial temporal lobe epilepsy seems to be determined by several factors including abnormalities in the expression and function of ion channels, such as the BK channel ${ }^{65}$. Liu et al ${ }^{70}$ demonstrated that BK channels are targeted by the E3 ubiquitin ligase CRL4A ${ }^{\text {CRBN }}$ for polyubiquitination and are therefore withheld in the endoplasmic reticulum (ER) and inhibited from trafficking to the cell membrane. Deregulation of this physiologic mechanism gives rise to a release of deubiquitinated BK channels from the ER to the plasma membrane, leading to significantly increased channel activity. Mice with the CRL4A ${ }^{\mathrm{CRBN}}$ mutation in the brain or treated with a CRL4A $\mathrm{A}^{\mathrm{CRBN}}$ inhibitor are very susceptible to seizure induction, which can be reduced by blocking BK 
channels (see below). Because the CRBN gene is widely expressed in the hippocampus, it plays a fundamental role in the development of limbic seizures ${ }^{70}$.

It has been demonstrated that the BK channel $\beta 4$-subunit reduces dentate gyrus excitability and protects against temporal lobe seizures, thus $\beta 4$ knockout mice present temporal lobe seizures emerging from the dentate gyrus ${ }^{56}$. Likewise, gain-of-function mutations, facilitating high-frequency neuronal firing, are (paradoxically) associated with spontaneous seizures in both rodents and humans. In fact, patients with generalized epilepsy (particularly absence epilepsy) and dyskinesia showed a point mutation in the RCK1 domain of the $\alpha$-subunit (i.e., D434G). This mutation increased the neuronal BK channel opening time, through enhancement of the voltage and $\mathrm{Ca}^{2+}$ sensitivity of the channel. Functionally, an increased activity of the BK channel and the consequent fAHP are associated with an enhanced membrane excitability. This augment seems to be caused by an enhanced recovery rate of the fast $\mathrm{Na}^{+}$current with a reduced refractory period of neuronal APs and/or through a disinhibition of thalamocortical circuits by blocking GABAergic interneurones ${ }^{20,53,68}$. It has been demonstrated that the presence of $\beta 1, \beta 2$, and $\beta 4$-subunits of BK channels enhances the D434G mutation. It was also reported that polymorphism in the $\beta 4$-subunit is associated with human epilepsy ${ }^{71}$.

The mitochondrial mitoBK has also been associated with various disorders including epilepsy; however, the mechanism by which functional deficits in mitoBK take part in epileptogenesis is unclear. Nevertheless, the possible role of these channels in suppressing seizures could be due both to a reduction of the production of reactive oxygen species (ROS) and to reduction of the accumulation of deleterious intra-mitochondrial $\mathrm{Ca}^{2+72}$. 


\section{Expert Opinion On Therapeutic Targets}

According to the above studies, the role of BK channels in various epileptogenic phenotypes can be highlighted. Usually, the activation of these types of channel leads to a reduced excitability. Therefore, it would be easy to propose that epilepsy might be treated with drugs that enhance the activation of $\mathrm{BK}$ channels, akin to the recent introduction of retigabine, a known M-type $\mathrm{K}^{+}$channel activator, in epilepsy management ${ }^{73}$. However, the actual realization may be far more controversial. Indeed, as mentioned above, epileptic phenotypes have also been associated with an increased activity of these channels (i.e. gain-of-function mutations). Moreover, the prediction of the outcome of these channel mutations is very complicated. Alternative splicing of $\mathrm{BK} \alpha \mathrm{KCNMA1}$ contributes to different complex phenotypes and various functional changes, including altered sensitivity to $\mathrm{Ca}^{2+}$ and/or voltage, responses to phosphorylation, signalling cascades, membrane expression regulation, trafficking and lipidation ${ }^{74}$. The functional heterogeneity that can appear after alternative splicing, polymorphisms, phosphorylation and protein interactions concerns the cytosolic domain. Some of these different phenotypes have been linked with epilepsy ${ }^{74,75}$. The phenotype of mutated BK channels varies not only among different tissues or cells, but also in the same tissue and cell type under different hormonal environments. The KCNMA1 gene has several alternative splice sites and alternative exons ${ }^{76}$. Two of these well-characterized splice isoforms, identified in the CNS, are the so-called stress axis hormone-regulated exon (STREX) and the ZERO variant. The STREX splice variant in comparison to the ZERO variant (that does not contain the STREX domain) contains a 58 amino acid cysteine-rich insert at the C2 splice site within the intracellular C-terminus RCK1-RCK2 linker of mammalian $\mathrm{BK}$ channels that confers increased $\mathrm{Ca}^{2+}$ sensitivity to the channel, thus changes the kinetics of the channel, and also alters some effects relating to channel phosphorylation by $\mathrm{PKA}^{7}$. In addition, it has been demonstrated that, gonadal (sex) and adrenal (stress) steroids 
participate in the regulation of the STREX splicing. Some studies have focused on the possible role of STREX expression for the pathogenesis of epilepsy ${ }^{39,77}$.

\section{BK channel modulators as potential antiepileptics}

The potassium channel superfamily represents a rich source of potential targets for therapeutic intervention. In view of the likely role of BK channels in the aetiology of epilepsy and other neurological disorders ${ }^{24}$, a major goal would be to discover selective activators, modulators and blockers of these channels, which could be useful in epilepsy therapy and perhaps also for treating many other central and peripheral vascular diseases ${ }^{78}$. The activity of BK channels is known to be modulated by many endogenous factors, such as acidification, phosphorylation, $\mathrm{NO}, \mathrm{Zn}^{2+}$, ROS, methionine oxidation, cholesterol, arachidonic acid, unsaturated free fatty acids such as the omega-3 docosahexaenoic acid and hormones (17 $\beta$-estradiol and other sex and stress steroids). Therefore, drugs that affect the generation of these factors would be expected to also modify BK channel activity. In agreement with this notion, some known endogenous modulators have been used as a basis for the development of novel compounds with BK channel modulatory activity. Notably, some of these compounds regulate BK channel function in an $\beta$-subunit dependent manner ${ }^{79,80}$. However, also natural and synthetic compounds may modulate BK channel activation. Among natural compounds, terpenes, phenols and flavonoids are able to stimulate BK channels ${ }^{81}$, but also represent an interesting group of compounds that could be used as a suitable scaffold to discover novel BK activators $^{52}$.

\section{[Table 1 near here]}

\subsection{BK channel openers/activators in epilepsy}




\section{Expert Opinion On Therapeutic Targets}

Studies have reported the effects of the anorexogenic hormone leptin and insulin to reduce epileptiform-like activity in rats and mice hippocampal neurones. Leptin inhibits hippocampal neurones by activation of BK channels and K(ATP) channels, a process that can be important in regulating neuronal excitability. It seems that the process leading to activation of BK channels involves stimulation of phosphoinositide 3-kinase (PI 3-kinase), but not mitogenactivated protein kinase (MAPK). Exactly the opposite has been observed for insulin. Indeed, insulin inhibits neuronal excitability via a process involving MAPK-driven activation of BK and K(ATP) channels. Leptin effects were mimicked by the synthetic BK channel activator NS1619 (1,3-dihydro-1-[2-hydroxy-5-(trifluoromethyl)phenyl]-5-(trifluoromethyl)-2Hbenzimidazol-2-one), and inhibited by the BK channel inhibitors, iberiotoxin and charybdotoxin. Therefore, this novel action of these hormones could be an alternative therapeutic target in the management of epilepsy. Recently, it was argued that the neuroprotective effects of leptin in NMDA-exposed cortical neurones in vitro, were dependent on BK channel activation, supporting the potential of targeting these channels in neurodegenerative diseases ${ }^{82,83}$.

The BK channel openers, isopimaric acid, chlorzoxazone (and NS1619) have been demonstrated to moderate inhibition of epileptiform activity induced by 4-aminopyridine (4AP) in cultured rat hippocampal neurones, whereas other BK channels openers such as NS309, DCEBIO, and 1-EBIO showed potent antiepileptic-anti-epileptiform effects similar to conventional antiepileptic drugs (AEDs) ${ }^{82-84}$. The use of NS1619 is however, limited by a relatively poor potency. In view of this poor activity, NS1619 was used as scaffold to generate the biarylthiourea NS11021, a potent compound useful to study the role of BK channels. Unfortunately, to date, there are no reports that link this compound with epilepsy. 
A variety of small synthetic molecules (NS004, fenamates) and natural product-derived compounds (DHS-I, maxikdiol) have also been identified as selective BK channel openers, which could have some useful effects ${ }^{85}$. Riluzole, a drug approved in the treatment of motoneurone disease, has been found to stimulate BK channels in rat pituitary GH3 cells ${ }^{86}$. The efficacy of riluzole against seizures in several animal models was previously reported ${ }^{87}$, ${ }^{88}$; however, the contribution of BK channels to the anticonvulsant effects of riluzole certainly needs to be further investigated.

It was asserted that oestrogen and xenoestrogens may modulate BK channels, and, for some of these steroids, the presence of a $\beta$-subunit seems to be pivotal for their action. However, the binding site and exact mechanism of action of these compounds are unknown ${ }^{89,} 90$. Hormones, such as oestrogens, play an important role in epilepsy ${ }^{91,92}$. Tamoxifen, a selective oestrogen-receptor modulator, seems to bind to these channels on the extracellular side. It has been shown that tamoxifen enhances the antiseizure efficacy of some AEDs against electrically and pentylenetetrazole-induced seizures in mice. These antiepileptic effects of tamoxifen could also be the consequence of BK channel modulation ${ }^{93,94}$.

Zonisamide (ZNS), a second generation antiepileptic drug, has also demonstrated its clinical efficacy in treating neuropsychiatric disorders. The precise antiepileptic mechanism of ZNS (possessing a sulphonamide side chain) is still unclear. ZNSIt is known to act possesses several mechanisms of action such asthrough the inhibition of voltage-gated $\mathrm{Na}^{+}$and $\mathrm{Ca}^{2+}$ channels and inhibition of carbonic anhydrase (CA $)^{95,96}$ Hower, Huang et al, have also demonstrated that ZNS increases the activity of BK channels with a related increment in the amplitude of $\mathrm{K}^{+}$outward current in hippocampal neurones ${ }^{97}$. mechanisms of aetion such as inhibition of voltage- $\mathrm{Na}^{-}$and $\mathrm{Ca}^{2}{ }^{2-}$ channels and 


\section{Expert Opinion On Therapeutic Targets}

inhibition of earbonic anhydrase $(\mathrm{CA})_{4,97}^{96,97}$ These latterCA inhibitors, such as acetazolamide (also a sulphonamide), are known to have anticonvulsant activity, and a similar mechanism might also contribute to the anticonvulsant effects of topiramate (an $O$-sulphamate derivative $)^{98}$. It has been demonstrated that acetazolamide, at concentrations higher than those required for the inhibition of $\mathrm{CA}$, were able to activate $\mathrm{BK}$ channels in skeletal muscle. Therefore, the antiepileptic effect of CA inhibitors could also be related the activation of these channels in neurones ${ }^{99,100}$. However, CA inhibitors might also influence BK channel activity by altering brain $\mathrm{pH}$. Similarly, COX-2 is known to be rapidly induced during seizures, and COX-2 inhibitors have been demonstrated to possess 102. Since arachidonic acid is known to activate BK channels, the relevance of COX-2 inhibition and arachidonic acid metabolism to the anticonvulsant action of such drugs needs to be further studied and defined ${ }^{103,104}$.

\section{[Table 2 near here]}

In several animal models, it has been demonstrated that the plasmalemma BK channels are sensitive to membrane cholesterol, their activity being depressed by a rise in levels and vice versa. Considering that AEDs are known to raise total plasma cholesterol levels in patients ${ }^{105}$, ${ }^{106}$, it would be of interest to determine whether BK channels play a role. The suggested anticonvulsant and antiepileptogenic effects possessed by some statins however may not be related to changes in cholesterol metabolism ${ }^{79,}$ 105, 107-109. Long-chain omega-3 polyunsaturated fatty acids, such as docosahexaenoic acid (DHA), found in oily fish are able to activate BK channels. Moreover, DHA decreases seizures in animal models of epilepsy in addition to having neuroprotective effects ${ }^{110,111}$. It has been reported that derivatives of the alkaloid eburnamine (derived from the Apocynaceae plant family), such as vinpocetine, are able to stimulate BK channels in pituitary GH3 rat cells. Vinpocetine has shown 


\subsection{BK channel blockers in epilepsy}

Previous studies (described above) have identified the ability of gain-of-function mutations giving rise to seizures both in rodent models and humans. Moreover, these studies have also reported that seizures themselves lead to up-regulation of BK channel currents with consequent elevated network excitability. In particular, this correlation has been observed in experimental models of generalized tonic-clonic seizures induced by the $\mathrm{GABA}_{\mathrm{A}}$ receptor/ion channel blocker picrotoxin and other chemoconvulsants. The elevated excitability in neocortical neurones induced by picrotoxin leads to generalized epilepsy that can be reduced by the BK channel antagonist paxilline. According to this, also other drugs that bind and block BK channels might decrease seizures. Studies have shown both the anticonvulsant effects of antiarrhythmic drugs, such as verapamil, and the ability of some of these drugs to inhibit BK channels. Therefore, it would be interesting to investigate the potential link between the effects of antiarrhythmics on BK channels and their anticonvulsant effects ${ }^{118-123}$. Likewise, the absence antiepileptic drug ethosuximide ${ }_{2}$ approved for the treatment of absence seizures, in addition to its activity on $\mathrm{Ca}_{\mathrm{v} 3}$ (T-type) channels, is also able to inhibit neuronal BK channels, thus this mechanism might also contribute to its antiepileptic activity ${ }^{119,124}$. 


\section{Expert Opinion On Therapeutic Targets}

\section{BK channels and cannabinoids in epilepsy}

Studies have shown the potential role of phyto- and endocannabinoids as novel therapeutic agents in CNS disorders, such as epilepsy and neurodegenerative diseases. However, psychotropic effects of these agents limit their therapeutic use ${ }^{125}$. Recently, some phytocannabinoids without psychotropic effects were found to improve CNS disorders like epilepsy. These nonpsychotropic compounds, such as cannabidivarin (CBDV) and cannabidiol (CBD) produce many pharmacological effects that are not mediated by or are partly mediated through putative $\mathrm{CB} 1 / \mathrm{CB} 2$ cannabinoid receptors. For this reason, various studies have been performed to explain the antiepileptic effects of these nonpsychotropic compounds, and clarify their potential mechanisms of action. It seems that among their potential target effects, two different channels, namely TRPV (transient receptor potential vanilloid) and BK, could directly or indirectly be involved ${ }^{126}$. This point is also supported by the central effects of $N$-palmitoylethanolamine (PEA) against pain and seizures ${ }^{127-129}$. PEA is an endogenous fatty acid amide analogue of the endocannabinoid anandamide ( $N$-arachidonylethanolamine; AEA) and it is produced on-demand within the neuronal membrane lipid bilayer; it has several proposed mechanisms of action including PPAR- $\alpha$ (peroxisome proliferator-activated receptor-alpha) activation ${ }^{130}$. Recently, it was proposed that BK channels may act as short-term intermediates for PPAR- $\alpha$ anti-nociceptive actions ${ }^{129,131}$.

A further link between the endocannabinoid system and epilepsy was also recently suggested by Shirazi-zand et al. ${ }^{132}$; it was demonstrated that the intracerebroventricular administration of CBD increases seizure threshold for PTZ-induced tonic seizures. The BK channel blocker, paxilline did not produce significant changes in seizure threshold when administrated alone. However, when paxilline was administrated together with $\mathrm{CBD}$, it was able to decrease the 


\section{Conclusions}

BK channels are widely distributed in the CNS, both in the cell body and at the presynaptic terminal; the most abundant level of BK channels is found in brain areas largely involved in epilepsy, namely cortex, hippocampus, piriform cortex, and other limbic structures. This wide distribution emphasizes their contribution in the control of CNS excitability. BK channels are responsible for the generation of the fAHP seen immediately after an AP. BK channels through the control of AP shape and duration, have an important function in regulating membrane excitability and $\mathrm{Ca}^{2+}$ signalling. Physiologically, an increase in $\mathrm{K}^{+}$conductance might correspond to a reduction in cell excitability; however, BK channels seem to have a modulatory effect, which might lead to increased excitability when their function is either increased or decreased. In agreement, BK channels have been demonstrated to either inhibit or enhance firing frequency in rat hippocampal CA1 pyramidal cells. This ability is directly connected to the shape of APs. Not surprisingly, BK channels are physiologically highly modulated by several endogenous modulators. Finally, the role of such channels in the CNS is further complicated by their ability to modulate neurotransmitter release.

In theory, under physiological conditions, through a negative feedback mechanism, BK channels modulate both neuronal membrane potential and intracellular $\mathrm{Ca}^{2+}$ signalling, 


\section{Expert Opinion On Therapeutic Targets}

\section{Expert Opinion}

The $\mathrm{K}^{+}$channel superfamily represents a rich source of potential targets for therapeutic intervention. As previously mentioned, retigabine is the only selective modulator drug (acting on M-type $\mathrm{K}^{+}$) channels currently marketed for the treatment of epilepsy. The validity of $\mathrm{K}^{+}$

actions that should attenuate epileptic seizure bursts. The actual sketch is actually intriguing and controversial, since mechanisms altering the physiological role of these channels, such as gene mutations, leading to both a loss- or gain-of-function have been linked to seizure onset. Usually, the activation of these types of channel leads to a reduced excitability. Therefore, it would be easy to propose that epilepsy might be treated with drugs that enhance the activation of BK channels.

Surprisingly, only few studies have addressed the effects of selective BK channel openers in epilepsy models and no proconvulsant effects have been reported to date (summarized in Table 1). On the other hand, the BK channel blocker paxilline showed consistent anticonvulsant effects in various animal models of epilepsy. However, the efficacy of paxilline has been observed in models where a gain-of-function was observed. Indeed, paxilline has anticonvulsant effects in the MES model where the function of these channels might not be altered. Noteworthy, paxilline does not have any effect against PTZ-induced seizures while blocking the effects of CBD in the same model. Furthermore, it cannot be excluded that the anticonvulsant effects of the available BK channel modulators might be due to other off-target mechanisms of action possessed by these drugs, such as inhibition of $\mathrm{Ca}^{2+}$ $\underline{\text { channels }^{6}}$.

In conclusion, while BK channels are undoubtedly involved in the regulation of neuronal excitability, their role and the effects of their modulation in the potential management of epilepsy still remain widely controversial. 
channels as a suitable target is further supported by the current development of ICA-105665, a novel small molecule opening Kv7.2/7.3 and Kv7.3/7.5 potassium channels, also known as $\mathrm{KCNQ} 2 / 3$ and KCNQ3/5 channels. This compound has shown a broad spectrum of activity in epilepsy/seizure animal models and epileptic patients ${ }^{133}$. Finally, several available AEDs are also acting on $\mathrm{K}^{+}$channels among their multiple mechanisms of action; e.g. topiramate, oxcarbazepine, lamotrigine, carbamazepine, ethosuximide ${ }^{98,124,134-137}$.

Despite the great number of marketed AEDs, there is still a great need for more effective, specific and safer drugs ${ }^{28}$. In this light, both clinical and preclinical research in this field is clearly looking for new directions to be followed in agreement with the strong need to modify the current approach which has been followed up to date ${ }^{28}$.

Considering BK channels, the results obtained so far, in the understanding of their physiological and pathological role in several neurological diseases including epilepsy, strongly encourage further studies. It is clear that BK channels have a great influence in the regulation of neuronal excitability and alterations in their function can represent both the cause and the consequence of seizures and epilepsy. It is easy to believe that BK channels must be considered a suitable target for new AED development; however, the current knowledge does not allow clear-cut conclusions.

Substantial data have identified mutations and alterations in the function of BK channels both in epileptic patients and epilepsy animal models; therefore, there is no doubt that they are involved in the hyperexcitation observed in the epileptic brain. Unfortunately, the physiology of this channel allows the possibility that either an impairment or increase in BK function can lead to hyperexcitability. This latter point implies a difficulty in predicting their role even if an alteration is identified. Namely, if a gain-of-function is found ${ }_{2}$ this might either be the cause or a defence mechanism for seizures. To this aim, the only available option is to directly test the effects of a BK channel agonist or antagonist; obviously, this is not a feasible clinical 


\section{Expert Opinion On Therapeutic Targets}

The potential of this research area is likely to be enormous, but assessing the risk/benefit ratio of all drugs acting on BK channels will be a great challenge. While several drugs modulating BK channels are available, data in epilepsy models are very limited. We believe that a better activity profile should be performed in order to understand whether these channels really represent a suitable target for AED development. On the other hand, it is very interesting and represents a good resource, the observation that several hormones and drugs with anticonvulsant activity can act on BK channels among their mechanisms of action; e.g. leptin,

approach. Therefore, the first weakness of this research area is the clear need for an improvement in the understanding of the function of this channel in pathological conditions. Bearing in mind this variability, the therapeutic success of drugs acting on BK channels will be highly influenced by predictors of activity in specific syndromes; furthermore, paradoxical effects might be expected in some others. This latter consideration rises from the observation that both BK channel blockers and openers possess potential anticonvulsant/antiepileptic effects. The BK channel blocker paxilline was found to be anticonvulsant in some models while blocking the anticonvulsant effects of CBD in another one. BK channels contribute to the fAHP and therefore their activation should be considered as a valid tool to decrease neuronal excitability; in other words, BK channel blockers should always be pro-convulsant or at least reduce seizure threshold. However, there are no reports for paxilline being proconvulsant. The complexity brought by modulation of BK channels is reflected by the suggestion that over-activation increases AP firing rate and therefore might contribute to seizure generation and spreading; these data support the anticonvulsant effects of paxilline and/or other BK blockers in some types of seizures where this mechanism is involved. On the other hand, the possible anticonvulsant effects of BK openers might instead drive an increase in firing rate, precipitating the generation of seizures. 
Overall, BK channels are certainly a suitable target for the development of drugs to be used in the epilepsy field as well as other neurological disorders. However, the whole area seems to hide behind a curtain and the entire portrait appears to be far from being finished. Nevertheless, the high degree of potential modulation of these channels (natural and druginduced) might offer a new approach for their future pharmacological targeting further than indicating that BK channels have a pivotal role in several CNS functions.

insulin, riluzole, zonisamide, acetazolamide, COX-2 inhibitors, DHA and andolast (Table 2). All these drugs were found to be openers/activators of BK channels, further supporting the idea that an increase in the function of these channels decreases excitability and therefore might contribute to the final anticonvulsant effects observed. Therefore, very selective drugs should be studied to understand their real value and the role of BK channels in epilepsy, whereas, the contribution of BK channel modulation to the anticonvulsant effects of the abovementioned drugs might indicate their potential as add-on therapies.

Finally, a very interesting area which has not previously been covered, is the role of BK channels in epileptogenesis. BK channels were found to be altered by the epileptogenic process in animal models and it remains completely unclear whether this is an adaptive response leading to the development of spontaneous seizures, or a defence response. The available data support the idea that a loss-of-function is linked to the development of spontaneous seizures and therefore, BK channels would underlie the epileptogenic process. In this light, it is not surprising that zonisamide (a BK channel activator) has antiepileptogenic effects in the WAG/Rij rat absence epilepsy model and that in the same strain, an alteration in the function of BK channels has been described ${ }^{95,138}$. 


\section{Acknowledgments}

None

\section{Conflict of Interest}

The authors have no conflict of interest to be disclosed. 


\begin{tabular}{|c|c|c|c|c|}
\hline$\underline{\text { Drugs }}$ & $\begin{array}{l}\frac{\text { Effect on }}{\text { BK }} \\
\text { Channels } \\
\end{array}$ & $\frac{\text { Experimental }}{\underline{\text { model }}}$ & $\underline{\text { Effects }}$ & $\underline{\text { Ref. }}$ \\
\hline$\underline{\text { Andolast }}$ & $\underline{\text { Activator }}$ & $\underline{\text { Pentylenetetrazole }}$ & $\begin{array}{l}\text { Enhances the anticonvulsive } \\
\text { activity of some antiepileptic } \\
\text { drugs. }\end{array}$ & 116 \\
\hline $\begin{array}{l}\frac{\text { Charybdotoxin }}{\text { (aggravates }} \\
\text { seizures) }\end{array}$ & $\underline{\text { Inhibitor }}$ & $\begin{array}{l}\text { Cultured rat } \\
\text { hippocampal } \\
\text { neurones }\end{array}$ & $\begin{array}{l}\text { Increases neurone } \\
\text { excitability }\end{array}$ & 82,83 \\
\hline Chlorzoxazone & $\underline{\text { Activator }}$ & $\begin{array}{l}\text { 4-Aminopyridine in } \\
\text { cultured rat } \\
\text { hippocampal } \\
\text { neurones }\end{array}$ & $\begin{array}{l}\text { Inhibits epileptiform activity } \\
\text { induced by 4-Aminopyridine }\end{array}$ & 85 \\
\hline $\begin{array}{l}\frac{\text { Iberiotoxin }}{\text { (aggravates }} \\
\text { seizures) }\end{array}$ & $\underline{\text { Inhibitor }}$ & $\begin{array}{l}\frac{\text { Cultured rat }}{\text { hippocampal }} \\
\text { neurones }\end{array}$ & $\begin{array}{l}\text { Increases neurone } \\
\text { excitability }\end{array}$ & 82,83 \\
\hline Insulin & Activator & $\begin{array}{l}\frac{\text { Cultured rat }}{\text { hippocampal }} \\
\underline{\text { neurones }}\end{array}$ & $\begin{array}{l}\text { Inhibits neuronal excitability } \\
\text { via a process involving } \\
\text { MAPK-driven activation of } \\
\text { BK and K(ATP) channels } \\
\end{array}$ & 82 \\
\hline Isopimaric acid & $\underline{\text { Activator }}$ & $\begin{array}{l}\text { 4-Aminopyridine in } \\
\text { cultured rat } \\
\underline{\text { hippocampal }} \\
\underline{\text { neurones }}\end{array}$ & $\begin{array}{l}\text { Inhibits epileptiform activity } \\
\text { induced by 4-Aminopyridine }\end{array}$ & 85 \\
\hline Leptin & $\underline{\text { Activator }}$ & $\begin{array}{l}\frac{\text { Cultured rat }}{\text { hippocampal }} \\
\text { neurones }\end{array}$ & $\begin{array}{l}\text { Regulateshippocampal } \\
\text { neurone excitability }\end{array}$ & 83 \\
\hline$\underline{N S 1619}$ & Activator & $\begin{array}{l}\text { 4-Aminopyridine in } \\
\text { cultured rat } \\
\text { hippocampal } \\
\text { neurones }\end{array}$ & $\begin{array}{l}\text { Inhibits epileptiform activity } \\
\text { induced by 4-Aminopyridine }\end{array}$ & $81-85$ \\
\hline $\begin{array}{l}\text { Paxilline (where } \\
\text { gain-of-function } \\
\text { was observed) }\end{array}$ & Inhibitor & $\begin{array}{l}\text { Chemoconvulsant } \\
\underline{\text { models }}\end{array}$ & $\begin{array}{l}\text { Reduces seizure duration and } \\
\underline{\text { severity }}\end{array}$ & $\begin{array}{l}118 \\
119 \\
121 \\
132\end{array}$ \\
\hline
\end{tabular}


Table 2. Drugs with known anticonvulsant activity, which may also act on BK channels

\begin{tabular}{|c|c|c|}
\hline Ligands & Evidence & References \\
\hline Acetazolamide & $\begin{array}{l}\text { - Anticonvulsant activity } \\
\text { - At high concentrations, binds to BK channels } \\
\text { in skeletal muscle }\end{array}$ & 99,100 \\
\hline Cannabidiol (CBD) & $\begin{array}{l}\text { Link between cannabis, epilepsy and BK channels } \\
\text { might exist }\end{array}$ & $\begin{array}{l}126,127,130, \\
132\end{array}$ \\
\hline COX-2 inhibitors & $\begin{array}{l}\text { - Antiepileptic effects } \\
\text { - Arachidonic acid is known to activate BK } \\
\text { channels }\end{array}$ & $52,103,104$ \\
\hline $\begin{array}{l}\text { Docosahexaenoic } \\
\text { Acid (DHA) }\end{array}$ & $\begin{array}{l}\text { Activates BK channels } \\
\text { DHA decreases seizures } \\
\end{array}$ & $52,80,110,111$ \\
\hline Ethosuximide & $\begin{array}{ll}\text { - } & \text { Approved AED } \\
& \text { Inhibits neuronal BK channels } \\
\end{array}$ & 124 \\
\hline$\underline{\text { Riluzole }}$ & $\begin{array}{ll} & \text { Stimulates BK channels in rat pituitary GH3 } \\
\text { cells } & \text { The efficacy of riluzole against seizures in } \\
\text { several animal models was previously reported }\end{array}$ & 87,88 \\
\hline$\underline{\text { Statins }}$ & $\begin{array}{ll} & \text { Anticonvulsant and antiepileptogenic effects } \\
\text { BK channel activity is sensitive to membrane } \\
\text { cholesterol }\end{array}$ & $52,79,107,108$ \\
\hline$\underline{\text { Tamoxifen }}$ & $\begin{array}{l}\text { - Enhances antiseizure activity of some AEDs } \\
\text { - Binds to BK channels }\end{array}$ & $90,93,139$ \\
\hline$\underline{\text { Vinpocetine }}$ & $\begin{array}{ll} & \text { Stimulates BK channels } \\
& \text { Exerts neuroprotective properties } \\
\end{array}$ & 112,113 \\
\hline Zonisamide & $\begin{array}{ll}\text { - } & \text { Approved AED } \\
& \text { Increases the activity of BK channels } \\
\end{array}$ & 95,97 \\
\hline
\end{tabular}




\section{References}

1. Sah $\mathrm{P} . \mathrm{Ca}(2+)$-activated $\mathrm{K}+$ currents in neurones: types, physiological roles and modulation. Trends Neurosci 1996; 19:150-4.

2. Vergara C, Latorre R, Marrion NV, Adelman JP. Calcium-activated potassium channels. Curr Opin Neurobiol 1998; 8:321-9.

3. Martire M, Barrese V, D'Amico M et al. Pre-synaptic BK channels selectively control glutamate versus GABA release from cortical and hippocampal nerve terminals. J Neurochem $2010 ; 115: 411-22$.

4. Raffaelli G, Saviane C, Mohajerani MH et al. BK potassium channels control transmitter release at CA3-CA3 synapses in the rat hippocampus. J Physiol 2004; 557:147-57.

5. Jensen BS, Strobaek D, Olesen SP, Christophersen P. The Ca2+-activated K+ channel of intermediate conductance: a molecular target for novel treatments? Curr Drug Targets $2001 ; 2: 401-22$.

6. Bentzen BH, Olesen SP, Ronn LC, Grunnet M. BK channel activators and their therapeutic perspectives. Front Physiol 2014; 5:389.

7. N'Gouemo P. Targeting BK (big potassium) channels in epilepsy. Expert Opin Ther Targets 2011; 15:1283-95.

8. $\quad$ Singh H, Stefani E, Toro L. Intracellular BK(Ca) (iBK(Ca)) channels. J Physiol 2012; 590:5937-47.

9. Lee US, Cui J. BK channel activation: structural and functional insights. Trends Neurosci 2010; 33:415-23.

10. Faber ES, Sah P. Calcium-activated potassium channels: multiple contributions to neuronal function. Neuroscientist 2003; 9:181-94.

11. Salkoff L, Butler A, Ferreira G et al. High-conductance potassium channels of the SLO family. Nat Rev Neurosci 2006; 7:921-31. 


\section{Expert Opinion On Therapeutic Targets}

12. Yang J, Yang $\mathrm{H}$, Sun $\mathrm{X}$ et al. Interaction between residues in the $\mathrm{Mg} 2+$-binding site regulates BK channel activation. J Gen Physiol 2013; 141:217-28.

13. Hou S, Heinemann SH, Hoshi T. Modulation of BKCa channel gating by endogenous signaling molecules. Physiology (Bethesda) 2009; 24:26-35.

14. Xiong ZQ, Saggau P, Stringer JL. Activity-dependent intracellular acidification correlates with the duration of seizure activity. J Neurosci 2000; 20:1290-6.

15. Shipston MJ. Regulation of large conductance calcium- and voltage-activated potassium (BK) channels by S-palmitoylation. Biochem Soc Trans 2013; 41:67-71.

16. Shi J, Krishnamoorthy G, Yang $\mathrm{Y}$ et al. Mechanism of magnesium activation of calcium-activated potassium channels. Nature 2002; 418:876-80.

17. Alioua A, Li M, Wu Y et al. Unconventional myristoylation of large-conductance $\mathrm{Ca}(2)(+)$-activated $\mathrm{K}(+)$ channel (Slo1) via serine/threonine residues regulates channel surface expression. Proc Natl Acad Sci U S A 2011; 108:10744-9.

18. Toro L, Li M, Zhang Z et al. MaxiK channel and cell signalling. Pflugers Arch 2014; $466: 875-86$.

19. Cui J, Yang H, Lee US. Molecular mechanisms of BK channel activation. Cell Mol Life Sci 2009; 66:852-75.

20. Du W, Bautista JF, Yang $\mathrm{H}$ et al. Calcium-sensitive potassium channelopathy in human epilepsy and paroxysmal movement disorder. Nat Genet 2005; 37:733-8.

21. Peng Z, Sakai Y, Kurgan L et al. Intrinsic disorder in the BK channel and its interactome. PLoS One 2014; 9:e94331.

22. Ahluwalia J, Tinker A, Clapp LH et al. The large-conductance Ca2+-activated $\mathrm{K}+$ channel is essential for innate immunity. Nature 2004; 427:853-8.

23. Zhang L, Li X, Zhou R, Xing G. Possible role of potassium channel, big K in etiology of schizophrenia. Med Hypotheses 2006; 67:41-3. 
24. Laumonnier F, Roger S, Guerin P et al. Association of a functional deficit of the BKCa channel, a synaptic regulator of neuronal excitability, with autism and mental retardation. Am J Psychiatry 2006; 163:1622-9.

25. Pitkanen A, Lukasiuk K. Mechanisms of epileptogenesis and potential treatment targets. Lancet Neurol 2011; 10:173-86.

26. Jehi LE, Vezzani A. Novel concepts in epileptogenesis and its prevention. Neurotherapeutics 2014; 11:229-30.

27. Schmidt D, Friedman D, Dichter MA. Anti-epileptogenic clinical trial designs in epilepsy: issues and options. Neurotherapeutics 2014; 11:401-11.

28. French JA, White HS, Klitgaard H et al. Development of new treatment approaches for epilepsy: unmet needs and opportunities. Epilepsia 2013; 54 Suppl 4:3-12.

29. Wang B, Rothberg BS, Brenner R. Mechanism of beta4 subunit modulation of BK channels. J Gen Physiol 2006; 127:449-65.

30. Yan J, Aldrich RW. BK potassium channel modulation by leucine-rich repeatcontaining proteins. Proc Natl Acad Sci U S A 2012; 109:7917-22.

31. Zhang J, Yan J. Regulation of BK channels by auxiliary gamma subunits. Front Physiol 2014; 5:401.

32. Meera P, Wallner M, Song M, Toro L. Large conductance voltage- and calciumdependent $\mathrm{K}+$ channel, a distinct member of voltage-dependent ion channels with seven $\mathrm{N}$ terminal transmembrane segments (S0-S6), an extracellular $\mathrm{N}$ terminus, and an intracellular (S9-S10) C terminus. Proc Natl Acad Sci U S A 1997; 94:14066-71.

33. Wang L, Sigworth FJ. Structure of the BK potassium channel in a lipid membrane from electron cryomicroscopy. Nature 2009; 461:292-5.

34. Wu Y, Yang Y, Ye S, Jiang Y. Structure of the gating ring from the human largeconductance $\mathrm{Ca}(2+)$-gated $\mathrm{K}(+)$ channel. Nature 2010; 466:393-7. 


\section{Expert Opinion On Therapeutic Targets}

35. Meera P, Wallner M, Toro L. A neuronal beta subunit (KCNMB4) makes the large conductance, voltage- and $\mathrm{Ca} 2+$-activated $\mathrm{K}+$ channel resistant to charybdotoxin and iberiotoxin. Proc Natl Acad Sci U S A 2000; 97:5562-7.

36. Jiang Y, Lee A, Chen $\mathrm{J}$ et al. Crystal structure and mechanism of a calcium-gated potassium channel. Nature 2002; 417:515-22.

37. Zhang $\mathrm{G}$, Yang $\mathrm{H}$, Liang $\mathrm{H}$ et al. A charged residue in $\mathrm{S} 4$ regulates coupling among the activation gate, voltage, and Ca2+ sensors in BK channels. J Neurosci 2014; 34:12280-8.

38. Huanghe Yang JS, Guohui Zhang, Junqiu Yang, Kelli Delaloye, and Jianmin Cui. Activation of Slo1 BK channels by $\mathrm{Mg} 2+$ coordinated between the

voltage sensor and the RCK1 domains. Nature Structural Molecular Biology 2008; 15:11529.

39. Yuan P, Leonetti MD, Pico AR et al. Structure of the human BK channel Ca2+activation apparatus at 3.0 A resolution. Science 2010; 329:182-6.

40. Yuan P, Leonetti MD, Hsiung Y, MacKinnon R. Open structure of the Ca2+ gating ring in the high-conductance Ca2+-activated K+ channel. Nature 2012; 481:94-7.

41. Yi L, Morgan JT, Ragsdale SW. Identification of a thiol/disulfide redox switch in the human BK channel that controls its affinity for heme and CO. J Biol Chem 2010; 285:2011727.

42. Contreras GF, Neely A, Alvarez O et al. Modulation of BK channel voltage gating by different auxiliary beta subunits. Proc Natl Acad Sci U S A 2012; 109:18991-6.

43. Wallner M, Meera P, Toro L. Molecular basis of fast inactivation in voltage and Ca2+activated K+ channels: a transmembrane beta-subunit homolog. Proc Natl Acad Sci U S A $1999 ; 96: 4137-42$.

44. Berkefeld H, Sailer CA, Bildl W et al. BKCa-Cav channel complexes mediate rapid and localized Ca2+-activated K+ signaling. Science 2006; 314:615-20. 
45. Isaacson JS, Murphy GJ. Glutamate-mediated extrasynaptic inhibition: direct coupling of NMDA receptors to $\mathrm{Ca}(2+)$-activated $\mathrm{K}+$ channels. Neuron 2001; 31:1027-34.

46. $\mathrm{Hu} \mathrm{H}$, Shao LR, Chavoshy $\mathrm{S}$ et al. Presynaptic Ca2+-activated $\mathrm{K}+$ channels in glutamatergic hippocampal terminals and their role in spike repolarization and regulation of transmitter release. J Neurosci 2001; 21:9585-97.

47. Fahanik-Babaei J, Eliassi A, Saghiri R. How many types of large conductance $\mathrm{Ca}(+)(2)$-activated potassium channels exist in brain mitochondrial inner membrane: evidence for a new mitochondrial large conductance $\mathrm{Ca}(2)(+)$-activated potassium channel in brain mitochondria. Neuroscience 2011; 199:125-32.

48. Liu HW, Hou PP, Guo XY et al. Structural basis for calcium and magnesium regulation of a large conductance calcium-activated potassium channel with beta1 subunits. J Biol Chem 2014; 289:16914-23.

49. Bentrop D, Beyermann M, Wissmann R, Fakler B. NMR structure of the "ball-andchain" domain of KCNMB2, the beta 2-subunit of large conductance Ca2+- and voltageactivated potassium channels. J Biol Chem 2001; 276:42116-21.

50. Sanchez M, McManus OB. Paxilline inhibition of the alpha-subunit of the highconductance calcium-activated potassium channel. Neuropharmacology 1996; 35:963-8.

51. Tao J, Zhou ZL, Wu B et al. Recombinant expression and functional characterization of martentoxin: a selective inhibitor for BK channel (alpha + beta4). Toxins (Basel) 2014; 6:1419-33.

52. Nardi A, Olesen SP. BK channel modulators: a comprehensive overview. Curr Med Chem 2008; 15:1126-46.

53. Gu N, Vervaeke K, Storm JF. BK potassium channels facilitate high-frequency firing and cause early spike frequency adaptation in rat CA1 hippocampal pyramidal cells. J Physiol 2007; 580:859-82. 


\section{Expert Opinion On Therapeutic Targets}

54. Velumian AA, Carlen PL. Differential control of three after-hyperpolarizations in rat hippocampal neurones by intracellular calcium buffering. J Physiol 1999; 517 ( Pt 1):201-16.

55. Alix P, Venkatesan K, Scuvee-Moreau J et al. Mechanism of the medium-duration afterhyperpolarization in rat serotonergic neurons. Eur J Neurosci 2014; 39:186-96.

56. Brenner R, Chen QH, Vilaythong A et al. BK channel beta4 subunit reduces dentate gyrus excitability and protects against temporal lobe seizures. Nat Neurosci 2005; 8:1752-9.

57. Bond CT, Herson PS, Strassmaier $\mathrm{T}$ et al. Small conductance $\mathrm{Ca} 2+$-activated $\mathrm{K}+$ channel knock-out mice reveal the identity of calcium-dependent afterhyperpolarization currents. J Neurosci 2004; 24:5301-6.

58. Runden-Pran E, Haug FM, Storm JF, Ottersen OP. BK channel activity determines the extent of cell degeneration after oxygen and glucose deprivation: a study in organotypical hippocampal slice cultures. Neuroscience 2002; 112:277-88.

59. Matthews EA, Disterhoft JF. Blocking the BK channel impedes acquisition of trace eyeblink conditioning. Learn Mem 2009; 16:106-9.

60. Loot AE, Moneke I, Keseru B et al. 11,12-EET stimulates the association of BK channel alpha and beta(1) subunits in mitochondria to induce pulmonary vasoconstriction. PLoS One 2012; 7:e46065.

61. Augustynek B, Kudin AP, Bednarczyk P et al. Hemin inhibits the large conductance potassium channel in brain mitochondria: a putative novel mechanism of neurodegeneration. Exp Neurol 2014; 257:70-5.

62. Fahanik-Babaei J, Eliassi A, Jafari A et al. Electro-pharmacological profile of a mitochondrial inner membrane big-potassium channel from rat brain. Biochim Biophys Acta $2011 ; 1808: 454-60$.

63. Li B, Jie W, Huang L et al. Nuclear BK channels regulate gene expression via the control of nuclear calcium signaling. Nat Neurosci 2014; 17:1055-63. 
64. Pacheco Otalora LF, Hernandez EF, Arshadmansab MF et al. Down-regulation of BK channel expression in the pilocarpine model of temporal lobe epilepsy. Brain Res 2008; 1200:116-31.

65. Ermolinsky B, Arshadmansab MF, Pacheco Otalora LF et al. Deficit of Kcnma1 mRNA expression in the dentate gyrus of epileptic rats. Neuroreport 2008; 19:1291-4.

66. Hu S, Labuda MZ, Pandolfo M et al. Variants of the KCNMB3 regulatory subunit of maxi BK channels affect channel inactivation. Physiol Genomics 2003; 15:191-8.

67. Lorenz S, Heils A, Kasper JM, Sander T. Allelic association of a truncation mutation of the KCNMB3 gene with idiopathic generalized epilepsy. Am J Med Genet B Neuropsychiatr Genet 2007; 144B:10-3.

68. Wang B, Rothberg BS, Brenner R. Mechanism of increased BK channel activation from a channel mutation that causes epilepsy. J Gen Physiol 2009; 133:283-94.

69. Behr J, Gloveli T, Heinemann U. Kindling induces a transient suppression of afterhyperpolarization in rat subicular neurons. Brain Res 2000; 867:259-64.

70. Liu J, Ye J, Zou X et al. CRL4A(CRBN) E3 ubiquitin ligase restricts BK channel activity and prevents epileptogenesis. Nat Commun 2014; 5:3924.

71. Lee US, Cui J. \{beta\} subunit-specific modulations of BK channel function by a mutation associated with epilepsy and dyskinesia. J Physiol 2009; 587:1481-98.

72. Bindokas VP, Lee CC, Colmers WF, Miller RJ. Changes in mitochondrial function resulting from synaptic activity in the rat hippocampal slice. J Neurosci 1998; 18:4570-87.

73. Ben-Menachem E. Medical management of refractory epilepsy--practical treatment with novel antiepileptic drugs. Epilepsia 2014; 55 Suppl 1:3-8.

74. Johnson BE, Glauser DA, Dan-Glauser ES et al. Alternatively spliced domains interact to regulate BK potassium channel gating. Proc Natl Acad Sci U S A 2011; 108:20784-9. 


\section{Expert Opinion On Therapeutic Targets}

75. Ahrendt E, Kyle B, Braun AP, Braun JE. Cysteine string protein limits expression of the large conductance, calcium-activated K(+) (BK) channel. PLoS One 2014; 9:e86586.

76. Chen L, Tian L, MacDonald SH et al. Functionally diverse complement of large conductance calcium- and voltage-activated potassium channel (BK) alpha-subunits generated from a single site of splicing. J Biol Chem 2005; 280:33599-609.

77. Ermolinsky BS, Skinner F, Garcia I et al. Upregulation of STREX splice variant of the large conductance $\mathrm{Ca} 2+$-activated potassium $(\mathrm{BK})$ channel in a rat model of mesial temporal lobe epilepsy. Neurosci Res 2011; 69:73-80.

78. Shieh CC, Coghlan M, Sullivan JP, Gopalakrishnan M. Potassium channels: molecular defects, diseases, and therapeutic opportunities. Pharmacol Rev 2000; 52:557-94.

79. Dopico AM, Bukiya AN, Singh AK. Large conductance, calcium- and voltage-gated potassium (BK) channels: regulation by cholesterol. Pharmacol Ther 2012; 135:133-50.

80. Clarke AL, Petrou S, Walsh JV, Jr., Singer JJ. Modulation of BK(Ca) channel activity by fatty acids: structural requirements and mechanism of action. Am J Physiol Cell Physiol 2002; 283:C1441-53.

81. Nardi A, Calderone V, Chericoni S, Morelli I. Natural modulators of largeconductance calcium-activated potassium channels. Planta Med 2003; 69:885-92.

82. O'Malley D, Shanley LJ, Harvey J. Insulin inhibits rat hippocampal neurones via activation of ATP-sensitive $\mathrm{K}+$ and large conductance $\mathrm{Ca} 2+$-activated $\mathrm{K}+$ channels. Neuropharmacology 2003; 44:855-63.

83. Shanley LJ, O'Malley D, Irving AJ et al. Leptin inhibits epileptiform-like activity in rat hippocampal neurones via PI 3-kinase-driven activation of BK channels. J Physiol 2002; 545:933-44. 
84. Garduno J, Galvan E, Fernandez de Sevilla D, Buno W. 1-Ethyl-2-benzimidazolinone (EBIO) suppresses epileptiform activity in in vitro hippocampus. Neuropharmacology 2005; 49:376-88.

85. Kobayashi K, Nishizawa Y, Sawada $\mathrm{K}$ et al. $\mathrm{K}(+)$-channel openers suppress epileptiform activities induced by 4 -aminopyridine in cultured rat hippocampal neurons. J Pharmacol Sci 2008; 108:517-28.

86. Wu SN, Li HF. Characterization of riluzole-induced stimulation of large-conductance calcium-activated potassium channels in rat pituitary GH3 cells. J Investig Med 1999; 47:48495.

87. Borowicz KK, Sekowski A, Drelewska E, Czuczwar SJ. Riluzole enhances the antiseizure action of conventional antiepileptic drugs against pentetrazole-induced convulsions in mice. Pol J Pharmacol 2004; 56:187-93.

88. De Sarro G, Siniscalchi A, Ferreri G et al. NMDA and AMPA/kainate receptors are involved in the anticonvulsant activity of riluzole in DBA/2 mice. Eur J Pharmacol 2000; 408:25-34.

89. King JT, Lovell PV, Rishniw M et al. Beta2 and beta4 subunits of BK channels confer differential sensitivity to acute modulation by steroid hormones. J Neurophysiol 2006; 95:2878-88.

90. Dick GM, Hunter AC, Sanders KM. Ethylbromide tamoxifen, a membraneimpermeant antiestrogen, activates smooth muscle calcium-activated large-conductance potassium channels from the extracellular side. Mol Pharmacol 2002; 61:1105-13.

91. Reddy DS. Role of hormones and neurosteroids in epileptogenesis. Front Cell Neurosci 2013; 7:115. 


\section{Expert Opinion On Therapeutic Targets}

92. Citraro R, Russo E, Di Paola ED et al. Effects of some neurosteroids injected into some brain areas of WAG/Rij rats, an animal model of generalized absence epilepsy. Neuropharmacology 2006; 50:1059-71.

93. Zhang H, Xie M, Schools GP et al. Tamoxifen mediated estrogen receptor activation protects against early impairment of hippocampal neuron excitability in an oxygen/glucose deprivation brain slice ischemia model. Brain Res 2009; 1247:196-211.

94. Borowicz KK, Luszczki J, Swiader M et al. Influence of sexual hormone antagonists on the anticonvulsant action of conventional antiepileptic drugs against electrically- and pentylenetetrazol-induced seizures in mice. Eur Neuropsychopharmacol 2004; 14:77-85.

95. Russo E, Citraro R, Scicchitano F et al. Effects of early long-term treatment with antiepileptic drugs on development of seizures and depressive-like behavior in a rat genetic absence epilepsy model. Epilepsia 2011; 52:1341-50.

96. Biton V. Clinical pharmacology and mechanism of action of zonisamide. Clin Neuropharmacol 2007; 30:230-40.

97. Huang $\mathrm{CW}$, Huang $\mathrm{CC}, \mathrm{Wu} \mathrm{SN}$. Activation by zonisamide, a newer antiepileptic drug, of large-conductance calcium-activated potassium channel in differentiated hippocampal neuron-derived H19-7 cells. J Pharmacol Exp Ther 2007; 321:98-106.

98. Russo E, Constanti A. Topiramate hyperpolarizes and modulates the slow poststimulus AHP of rat olfactory cortical neurones in vitro. Br J Pharmacol 2004; 141:285301.

99. Thiry A, Dogne JM, Supuran CT, Masereel B. Anticonvulsant sulfonamides/sulfamates/sulfamides with carbonic anhydrase inhibitory activity: drug design and mechanism of action. Curr Pharm Des 2008; 14:661-71.

100. Tricarico D, Barbieri M, Mele A et al. Carbonic anhydrase inhibitors are specific openers of skeletal muscle BK channel of K+-deficient rats. FASEB J 2004; 18:760-1. 
101. Citraro R, Leo A, Marra R et al. Antiepileptogenic effects of the selective COX-2 inhibitor etoricoxib, on the development of spontaneous absence seizures in WAG/Rij rats. Brain Research Bulletin 2015.

102. Vezzani A, Friedman A, Dingledine RJ. The role of inflammation in epileptogenesis. Neuropharmacology 2013; 69:16-24.

103. Rojas A, Jiang J, Ganesh T et al. Cyclooxygenase-2 in epilepsy. Epilepsia 2014; $55: 17-25$.

104. Lu T, Wang XL, He T et al. Impaired arachidonic acid-mediated activation of largeconductance $\mathrm{Ca} 2+$-activated $\mathrm{K}+$ channels in coronary arterial smooth muscle cells in Zucker Diabetic Fatty rats. Diabetes 2005; 54:2155-63.

105. Kim DW, Lee SY, Shon YM, Kim JH. Effects of new antiepileptic drugs on circulatory markers for vascular risk in patients with newly diagnosed epilepsy. Epilepsia 2013; 54:e146-9

106. Chuang YC, Chuang HY, Lin TK et al. Effects of long-term antiepileptic drug monotherapy on vascular risk factors and atherosclerosis. Epilepsia 2012; 53:120-8.

107. Citraro R, Chimirri S, Aiello $\mathrm{R}$ et al. Protective effects of some statins on epileptogenesis and depressive-like behavior in WAG/Rij rats, a genetic animal model of absence epilepsy. Epilepsia 2014; 55:1284-91.

108. Russo E, Donato di Paola E, Gareri P et al. Pharmacodynamic potentiation of antiepileptic drugs' effects by some HMG-CoA reductase inhibitors against audiogenic seizures in DBA/2 mice. Pharmacol Res 2013; 70:1-12.

109. Stepien KM, Tomaszewski M, Luszczki JJ, Czuczwar SJ. The interactions of atorvastatin and fluvastatin with carbamazepine, phenytoin and valproate in the mouse maximal electroshock seizure model. Eur J Pharmacol 2012; 674:20-6. 


\section{Expert Opinion On Therapeutic Targets}

110. Hoshi T, Tian Y, Xu R et al. Mechanism of the modulation of BK potassium channel complexes with different auxiliary subunit compositions by the omega-3 fatty acid DHA. Proc Natl Acad Sci U S A 2013; 110:4822-7.

111. Taha AY, Jeffrey MA, Taha NM et al. Acute administration of docosahexaenoic acid increases resistance to pentylenetetrazol-induced seizures in rats. Epilepsy Behav 2010; $17: 336-43$.

112. Wu SN, Li HF, Chiang HT. Vinpocetine-induced stimulation of calcium-activated potassium currents in rat pituitary GH3 cells. Biochem Pharmacol 2001; 61:877-92.

113. Vas A, Gulyas B. Eburnamine derivatives and the brain. Med Res Rev 2005; 25:73757.

114. Revel L, Colombo S, Ferrari F et al. CR 2039, a new bis-(1H-tetrazol-5yl)phenylbenzamide derivative with potential for the topical treatment of asthma. Eur J Pharmacol 1992; 229:45-53.

115. Persiani S, D'Amato M, Makovec $\mathrm{F}$ et al. Pharmacokinetics of andolast after administration of single escalating doses by inhalation in mild asthmatic patients. Biopharm Drug Dispos 2001; 22:73-81.

116. Czuczwar SJ, Gasior M, Kozicka M et al. A potential anti-asthmatic drug, CR 2039, enhances the anticonvulsive activity of some antiepileptic drugs against pentetrazol in mice. Eur Neuropsychopharmacol 1998; 8:233-8.

117. Czuczwar SJ, Gasior M, Kozicka M et al. Influence of a potential anti-asthmatic drug, CR 2039, upon the anticonvulsive activity of conventional antiepileptics against maximal electroshock-induced seizures in mice. J Neural Transm 1996; 103:1371-9.

118. Shruti S, Clem RL, Barth AL. A seizure-induced gain-of-function in BK channels is associated with elevated firing activity in neocortical pyramidal neurons. Neurobiol Dis 2008; $30: 323-30$ 
119. Sheehan JJ, Benedetti BL, Barth AL. Anticonvulsant effects of the BK-channel antagonist paxilline. Epilepsia 2009; 50:711-20.

120. Borowicz KK, Banach M. Antiarrhythmic drugs and epilepsy. Pharmacol Rep 2014; 66:545-51.

121. De Sarro G, De Sarro A, Federico F, Meldrum BS. Anticonvulsant properties of some calcium antagonists on sound-induced seizures in genetically epilepsy prone rats. Gen Pharmacol 1990; 21:769-78.

122. Harper AA, Catacuzzeno L, Trequattrini $\mathrm{C}$ et al. Verapamil block of largeconductance Ca-activated K channels in rat aortic myocytes. J Membr Biol 2001; 179:103-11. 123. Asadi-Pooya AA, Razavizadegan SM, Abdi-Ardekani A, Sperling MR. Adjunctive use of verapamil in patients with refractory temporal lobe epilepsy: a pilot study. Epilepsy Behav 2013; 29:150-4.

124. Crunelli V, Leresche N. Block of Thalamic T-Type $\mathrm{Ca}(2+)$ Channels by Ethosuximide Is Not the Whole Story. Epilepsy Curr 2002; 2:53-6.

125. Szaflarski JP, Martina Bebin E. Cannabis, cannabidiol, and epilepsy - From receptors to clinical response. Epilepsy Behav 2014.

126. Iannotti FA, Hill CL, Leo A et al. Nonpsychotropic Plant Cannabinoids, Cannabidivarin (CBDV) and Cannabidiol (CBD), Activate and Desensitize Transient Receptor Potential Vanilloid 1 (TRPV1) Channels in Vitro: Potential for the Treatment of Neuronal Hyperexcitability. ACS Chem Neurosci 2014.

127. Citraro R, Russo E, Scicchitano $F$ et al. Antiepileptic action of Npalmitoylethanolamine through CB1 and PPAR-alpha receptor activation in a genetic model of absence epilepsy. Neuropharmacology 2013; 69:115-26. 


\section{Expert Opinion On Therapeutic Targets}

128. Sasso O, La Rana G, Vitiello S et al. Palmitoylethanolamide modulates pentobarbitalevoked hypnotic effect in mice: involvement of allopregnanolone biosynthesis. Eur Neuropsychopharmacol 2010; 20:195-206.

129. de Novellis V, Luongo L, Guida F et al. Effects of intra-ventrolateral periaqueductal grey palmitoylethanolamide on thermoceptive threshold and rostral ventromedial medulla cell activity. Eur J Pharmacol 2012; 676:41-50.

130. Mattace Raso G, Russo R, Calignano A, Meli R. Palmitoylethanolamide in CNS health and disease. Pharmacol Res 2014; 86:32-41.

131. LoVerme J, Russo R, La Rana G et al. Rapid broad-spectrum analgesia through activation of peroxisome proliferator-activated receptor-alpha. J Pharmacol Exp Ther 2006; 319:1051-61.

132. Shirazi-zand Z, Ahmad-Molaei L, Motamedi F, Naderi N. The role of potassium BK channels in anticonvulsant effect of cannabidiol in pentylenetetrazole and maximal electroshock models of seizure in mice. Epilepsy Behav 2013; 28:1-7.

133. Kasteleijn-Nolst Trenite DG, Biton V, French JA et al. Kv7 potassium channel activation with ICA-105665 reduces photoparoxysmal EEG responses in patients with epilepsy. Epilepsia 2013; 54:1437-43.

134. Herrero AI, Del Olmo N, Gonzalez-Escalada JR, Solis JM. Two new actions of topiramate: inhibition of depolarizing GABA(A)-mediated responses and activation of a potassium conductance. Neuropharmacology 2002; 42:210-20.

135. Poolos NP, Migliore M, Johnston D. Pharmacological upregulation of h-channels reduces the excitability of pyramidal neuron dendrites. Nat Neurosci 2002; 5:767-74.

136. White HS, Smith MD, Wilcox KS. Mechanisms of action of antiepileptic drugs. Int Rev Neurobiol 2007; 81:85-110. 
137. Wickenden AD. Potassium channels as anti-epileptic drug targets. Neuropharmacology 2002; 43:1055-60.

138. Ehling $\mathrm{P}$, Cerina M, Meuth $\mathrm{P}$ et al. $\mathrm{Ca}(2+)$-dependent large conductance $\mathrm{K}(+)$ currents in thalamocortical relay neurons of different rat strains. Pflugers Arch 2012.

139. Sha Y, Tashima T, Mochizuki Y et al. Compounds structurally related to tamoxifen as openers of large-conductance calcium-activated $\mathrm{K}+$ channel. Chem Pharm Bull (Tokyo) 2005; 53:1372-3.

\section{Figure legend}

\section{Figure 1}

The BK channel protein is a multimeric structure (homotetramer) composed of four identical pore-forming $\alpha$ subunits (BK $\alpha$ ), encoded by a single gene (Slol, KCNMA1). Each BKa has seven trans-membrane segments (S0-S6) and a large intracellular C-terminus region. The $\mathrm{BK} \alpha$ protein shows three main structural domains, each with a distinct function. The voltagesensing domain (VSD) is located within the S1-S4 trans-membrane segments, able to sense membrane potential. The S5-S6 segments form the pore gate domain (PGD) including the activation gate, which controls $\mathrm{K}^{+}$flux through the channel. The S6 segment serves as the major structural determinant for the channel gate. The primary voltage sensor is located on the S4 helix, which contains many positively charged residues, but only one of these participates in voltage sensing. The membrane-spanning domains VSD and PGD, interact through the S4-S5 linker and S6, and the hydrophobic segment (S0) leads to an extracellular $\mathrm{NH}_{2}$ terminus. The third domain is the cytosolic domain (CTD), which enables the channel to respond to changes in $\left[\mathrm{Ca}^{2+}\right]_{\mathrm{i}}$ and other stimuli. The intracellular $\mathrm{C}$-terminus has two tandem $\mathrm{RCK}$ (regulator of $\mathrm{K}^{+}$conductance) domains, RCK1 and RCK2, folded tightly against each other. Channel sensitivity to $\mathrm{Ca}^{2+}$ is determined by a gating ring of eight $\mathrm{RCK}$ domains from 


\section{Expert Opinion On Therapeutic Targets}

the four assembled $\alpha$ subunits; this gating ring is subjected to an expansion during channel gating. RCK2 domains have an aspartate-rich region that forms the ' $\mathrm{Ca}^{2+}$ bowl', showing a high $\mathrm{Ca}^{2+}$ affinity. A low-affinity $\mathrm{Ca}^{2+}$ recognition site has also been identified within the RCK1 domain, where another high-affinity $\mathrm{Ca}^{2+}$ site is also present. RCK1 also mediates the channel's sensitivity to $\mathrm{Mg}^{2+}, \mathrm{Zn}^{2+}$ and $\mathrm{Cd}^{2+}$. The four $\beta$-subunits ( $\left.\beta 1-4\right)$ are encoded by a specific gene KCNMB1-4 (human) or kcnmb1-4 (mouse). These BK channel subunits have

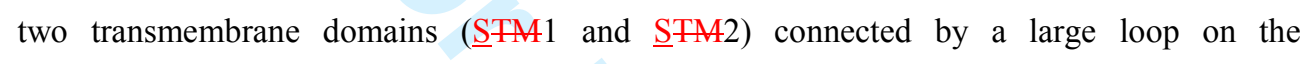
extracellular side. $\beta$-subunits also show an intracellular $\mathrm{N}$-terminus and $\mathrm{C}$-terminus. Each $\beta$ subunit is located between two adjacent $\alpha$-subunits. $\gamma$ subunits contain a single transmembrane domain, an N-terminal extracellular LRRD (leucine-rich repeat domain), and a short C-terminal tail. 